\title{
Lateral Basal Approach to CPA in Supine No-Retractor Method: Microvascular Decompression for Hemifacial Spasm
}

\author{
Katsuyoshi Shimizu ${ }^{1}$ \\ ${ }^{1}$ Department of Neurosurgery, Showa University School of Medicine, \\ Shinagawa-ku, Tokyo, Japan
}

J Neurol Surg B 2019;80(suppl S3):S318-S319.
Address for correspondence Katsuyoshi Shimizu, MD, Department of
Neurosurgery, Showa University School of Medicine, 5-8 Hatanodai 1,
Shinagawa-ku Tokyo 142-8666, Japan (e-mail: katsuyoshis@aol.com).

\begin{abstract}
Keywords

- more basal approach

- interlaminal fatty layer

- skull base

- hemifacial spasm

- microvascular decompression

Objectives In this video, we demonstrate our more basal approach in microvascular decompression for hemifacial spasm.

Design The patient is in supine position with the head rotated maximally to the opposite side on the U-shaped head rest. The small cranial window is made at the lateral bottom of occipital cranium with the adequate superficial manipulation on the muscles layers in the craniocervical junction.

Results The more basal approach enables the surgeon to access all the segments of the VIIth nerve tract without cerebellar retraction by spatula, especially in the case with vertebral artery associated compression.

Conclusion This approach safely provides the ideal operative corridor promising sufficient decompression in micorvascular decompression for the VIlth nerve. The link to the video can be found at: https://youtu.be/_nKSjGEHoB4.
\end{abstract}

Conflict of Interest

None.

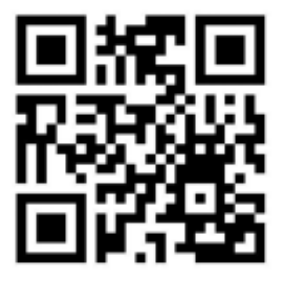

received

May 30, 2018

accepted

August 19, 2018

published online

October 23, 2018 www.thieme.com/skullbasevideos

www.thieme.com/jnlsbvideos

DOI https://doi.org/

10.1055/s-0038-1675166.

ISSN 2193-6331.
License terms

(c) $(1) \risingdotseq$ 


\section{Preoperative MRIs}

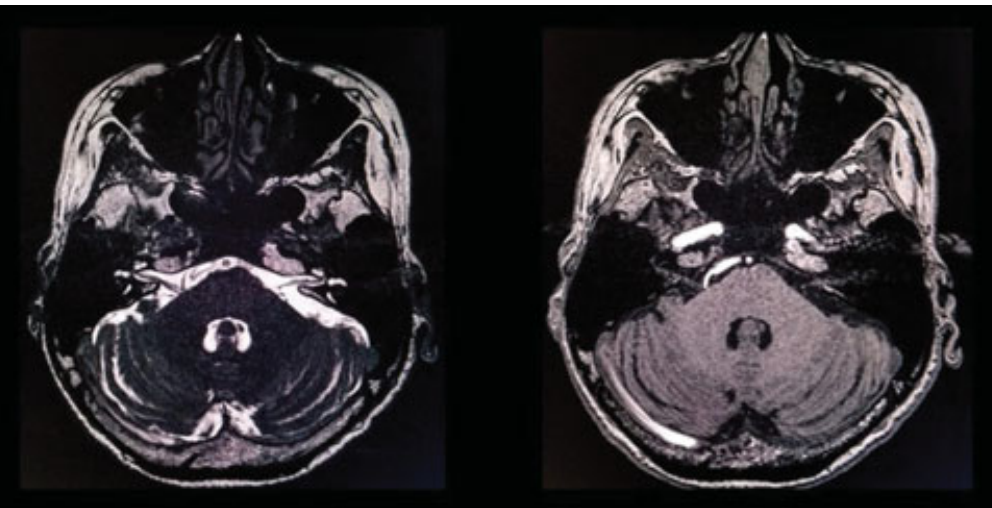

\section{Postoperative MRIs}

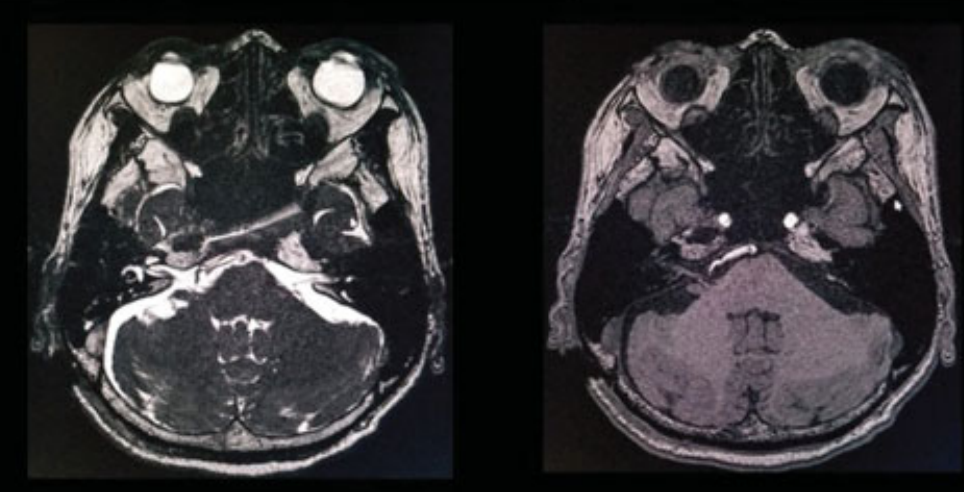

Fig. 1 Pre- and postoperative MRIs indicate decompression has been successfully done. MRI, magnetic resonance imaging.
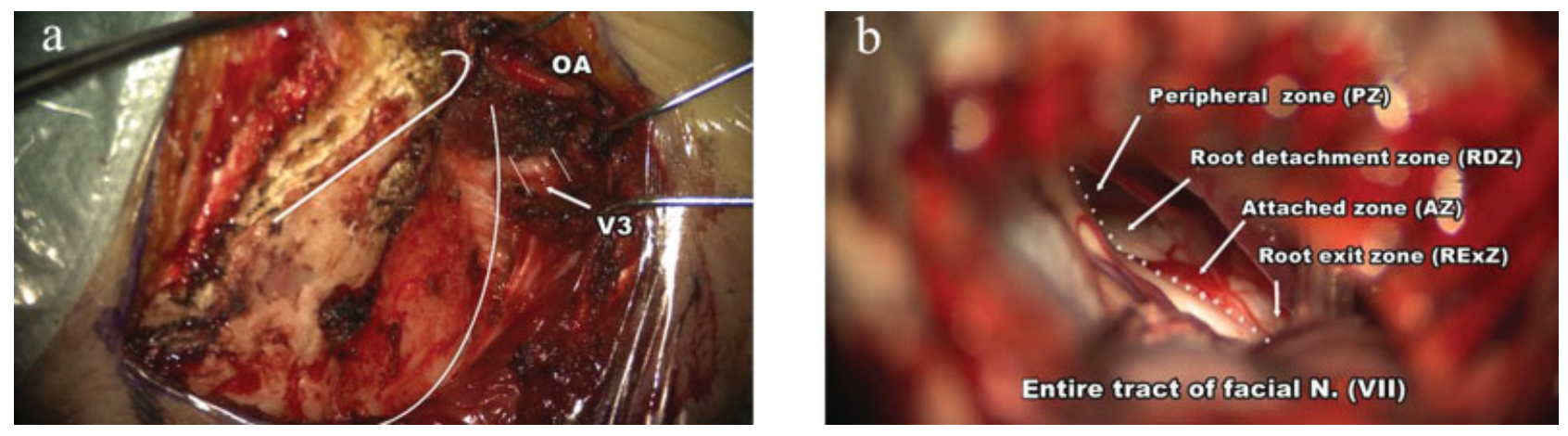

Fig. 2 (a) The superficial view after muscle preparation. The bottom of the occipital cranium has been disclosed. (b) The unique surgical corridor of this approach exposing the entire facial nerve tract. OA, occipital artery. 